\title{
SYNTHESIS OF NEW PHOTOSWITCHABLE LOCAL ANESTHETIC BASED ON FOTOCAINE AND ITS BIOLOGICAL PROPERTIES INVESTIGATION IN VIVO
}

\author{
A.N. Noev ${ }^{1,2}$, N.D. Kuznetsov' ${ }^{1}$, G. Korenev' ${ }^{1}$, A.Y. Bugrov', A.A. Pilyaev', \\ N.B. Morozova ${ }^{2}$, A.A. Pankratov² and M.A. Grin' \\ ${ }^{1}$ M.V. Lomonosov Institute of Fine Chemical Technologies, RTU MIREA, \\ 119571, Russia, Moscow, Vernadsky Avenue, 86. \\ 2Department of Experimental Pharmacology and Toxicology, National Medical Research \\ Radiological Centre of the Ministry of Health of the Russian Federation, \\ 125284, Russia, Moscow, 2nd Botkinskiy proezd, 3.
}

DOI: 10.19163/MedChemRussia2021-2021-546

E-mail: aleksej-noev@yandex.ru

Photopharmacology is a developing area of medicinal chemistry which use light to reversibly control the biological activity of the drug. Recently Schoenberger et al. successfully incorporated azobenzene moiety in structure of known local anesthetic fomocaine resulting in photoswitchable $\mathrm{Na}_{\mathrm{v}}$ channels blocker fotocaine with trans-cis photoisomerization wavelengths $\lambda=330-350 \mathrm{~nm}$ [1]. In this work the ether analogue of fotocaine was synthesized for the first time, which has enhanced trans-cis isomerization wavelength $\lambda=350-380 \mathrm{~nm}$ (Fig. 1). This absorption maximum shifting can reduce side effects of UV irradiation necessary for photoswitching.

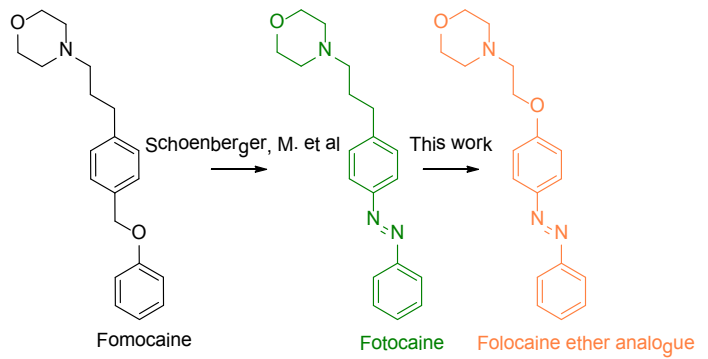

Fig. 1. Chemical structures of Fotocaine and its ether analogue

Fotocaine ether analogue was tested on surface anesthesia in vivo model on rabbits cornea in dark (for trans-configuration) and under UV $(\lambda=380 \mathrm{~nm})$ irradiation (for cis-configuration). Clear anesthetic effect $(n=5)$ was obtained in dark with almost no activity ( $n=5$ ) being observed under UV-irradiation. To our knowledge this is the first evidence of light-controlled local anesthesia in vivo.

Results of this work show the possibility of usage photoswitchable local anesthetics which can have reduced side-effects comparing with known drugs. Also this work underline the necessity of new photoswitchable Nav channel blockers development including red-shifted and cis-active ones.

\section{References}

[1] M. Schoenberger et al., ACS Chem. Neurosci. 2014, 5 (7), 514-518

$$
-546-
$$

